\title{
AN ANALYSIS OF INTERCULTURAL STUDENTS' SELF-DETERMINATION IN GRADUATE ONLINE PROGRAMMES: IMPLICATIONS FOR PRAXIS
}

\author{
Charmaine Bissessar[charmaine.bissessan@roehampton-online.ac.uk],University of Roehampton London \\ Online,Debra Black.[debrablack@2tim47.com],MehrazBoolaky[mebz51@yahoo.com],University of \\ Liverpool Management School Online Graduate Studies, United Kingdom
}

\begin{abstract}
The self-determination of online graduate students was studied in terms of the impact of autonomy, competence and relatedness upon their persistence. Unique to this study was the assessment of the potential influence of socio-cultural factors. As the majority of research into online university students' persistence is generated from the US, Canada, UK and European countries assessing their own domestic populations, the global nature of this study provides a new perspective. Fifty-four online graduate students representing 26 countries participated representing 19 lesser developed economies and 7 developed economies. Collectivist versus individualistic cultures were equally represented. Self-determination Theory (SDT) was examined both in terms of the online classroom environment as well as overcoming life challenges for programme perseverance. A correlational matrix was used to reject the null hypothesis. Results indicated that statistically significant correlations exist among the three variables, and, in the instances of the variables of autonomy and relatedness, a significant negative correlation exists. The findings indicate that the participants displayed strong internal locus of control, self-directed learning, competency and relatedness in attaining success within the online environment programme. Cultural communitarianism values were not found to be of significant influence.
\end{abstract}

\section{Abstract in French}

L'autodétermination des étudiants des cycles supérieurs en ligne a été étudiée en termes d'impact de l'autonomie, de la compétence et des relations entre eux sur leur persistance. L'évaluation de l'influence potentielle de facteurs socioculturels est unique à cette étude. La majorité des recherches sur la persistance des étudiants universitaires en ligne étant générées par les ÉtatsUnis, le Canada, le Royaume-Uni et les pays européens qui évaluent leurs propres populations nationales, la nature mondiale de cette étude offre une nouvelle perspective. Cinquante-quatre étudiants en ligne de cycles supérieurs représentant 26 pays, représentant 19 économies moins développées et 7 économies développées, ont participé. Les cultures collectivistes et individualistes étaient également représentées. La théorie de l'autodétermination (TSD) a été examinée à la fois en termes d'environnement de classe en ligne et de résolution des problèmes de la vie quotidienne liés à la persévérance des programmes. Une matrice de corrélation a été utilisée pour rejeter l'hypothèse nulle. Les résultats ont montré qu'il existait des corrélations statistiquement significatives entre les trois variables et qu'il existait une corrélation négative significative dans les cas des variables autonomie et relation. Les résultats indiquent que les participants ont montré un fort locus de contrôle interne, un apprentissage auto-dirigé, des compétences et une relation de proximité pour réussir dans le programme d'environnement en ligne. Les valeurs du communautarisme culturel n'ont pas eu d'influence notable.

Keywords: self-determination theory; cultural diversity, student motivation, online education, self-regulation 


\section{Introduction}

The study of students' self-determination within the online environment continues to be of critical importance and is considered to be a factor in retention (Chen \& Jang, 2010). Dietz Uhler et al. (2007) indicated that online retention rates are less than the face-to-face classrooms. However, Moore et al. (2003) suggested that this could be because of competition with other priorities within the students' lives (Kahn et al., 2017). The need to retain students and understand student motivation was further investigated by Harnett et al. (2011) who concluded that previous studies of online students' motivations focused on either trait-like characteristics or their intrinsic motivation. At the time of their study, the authors found little research on the interplay between the learner and his/her learning environment.

More recently, Filak and Nicolini (2018) identified potential changes to the three SDT components and online students' classroom experiences. Therefore, self-determination is a critical aspect of the online environment and one in which more research is needed as to how students' motivational needs are catered to in the design and structure of the online modules (Filak \& Nicolini, 2018; Khan et al., 2017). With the rapid growth in e-learning worldwide expected to surge beyond USD243 billion by 2022 (Statista, 2018), fresh research is important for the higher learning community to understand the nuances of the learning experience which lead to or inhibit students' success.

Indeed, poor motivation has been identified as a determining factor in online student retention (Muilenburg \& Berge, 2005 cited in Harnett et al. 2011). Chen and Jang (2010) underscored this and stated that high attrition rates can be an indication of a lack of motivation. Added to poor motivation is the diversity of the online student population which creates additional stress for students when collaborating within the classroom (Rumble \& Latchem, 2004). The same benefits derived from attending studies online, that of being able to defy time and space, become an issue when this diversity threatens students' motivational levels. In contrast to the views of Garrison (1997), Hartnett et al. (citing McCombs \& Vakili, 2005) question whether or not online students' can really be viewed as possessing the ability to problem-solve, to study independently, practice self-directed learning and be intrinsically motivated (2011). This relates to students' self-directed learning readiness as well, which was found to predict motivation and academic stress for 186 online Korean students (Heo \& Han, 2017). Additionally, research of online students' motivation echoes the view that more empirical studies are needed in order to fully understand the online students' drive to start and remain in an online programme (Miltiadou \& Savenye, 2003 in Harnett et al., 2011). With this in mind, the purpose of this study was to capture the level of online graduate students' self-determination of at University of Liverpool, specifically exploring the aspects of the self-determination theory (autonomy, competence and relatedness) exemplified by the participants in their persistence.

\section{Self-Determination Theory}

Motivation continues to be an issue in online education. One of the theories that encapsulates both intrinsic and extrinsic motivation is the self-determination theory (Deci \& Ryan, 1985 in Harnett et al., 2011). Moreover, definitions of self-determination indicate individual autonomy in the form of intrinsic motivation which propels the individual to work toward achieving a specific goal. From the extant literature, it is evident that researchers have conceptualized selfdetermination as trait-like, with less consideration of the dynamic interplay between the learner and his/her environment (Harnett et al., 2011). This can be evidenced in the definition by Ryan, Kuhl, and Deci (1997), who stated: 


\begin{abstract}
"SDT is an approach to buman motivation and personality that uses traditional empirical methods while employing an organismic metatheory that highlights the importance of humans' evolved inner resources for personality development and behavioural self-regulation." (p.701)
\end{abstract}

This definition sees the individual as possessing intrinsic motivation which is part of his/her personality, and, as a result, this innate motivation determines his/her external behaviours. Therefore, extrinsic motivation and intrinsic motivation are interrelated and interdependent.

Ryan and Deci (2000) further indicated that there are specific components of the selfdetermination theory that exemplify the innate nature of motivation and how it works with the personality. According to Durksen et al. (2016), there are three psychological needs which are seen as intrinsic motivators: competence (Harter, 1978; White, 1963); relatedness (Baumeister \& Leary, 1995; Reis, 1994), and autonomy (deCharms, 1968; Deci, 1975). "Autonomy has been defined as an individual's experience of volitional and freely chosen behaviours" (p.244). This definition is congruent with Filak and Nicolini's (2018) view that autonomy entails the individuals' belief about the extent to which they possess internal locus of control.

According to Durksen et al. (2016) "a learner may gain competence through a challenging activity (i.e., neither too difficult nor too easy) that allows an individual to feel effective in his or her environment" (p.244). This resonates with Filak and Nicolini's (2018) explanation that competence is the most concrete need of the three components of the self-determination theory since it is based on the accomplishment and mastery of tasks. Individuals who are competent tend to have meaningful outcomes and practise until they feel that they have mastered the particular task.

Relatedness indicates the connection individuals feel to people whom they value as important to them, in terms of the other person demonstrating understanding and not objectifying them. It is the most interpersonal of the three components of self-determination and is linked to the theory of sense of belonging (Filak \& Nicolini, 2018). Earlier, Baumeister and Leary (1995) linked sense of belonging to "frequent, non-aversive interactions within an ongoing relational bond sense" (p.497). Furthermore, they linked belongingness to improved emotional and cognitive patterns. In seeking relatedness, individuals "often strive to feel like they are part of a larger whole or making a connection with people whom they wish to impress" (Filak \& Nicolini, 2018; p.776). Filak and Nicolini further indicated that autonomy and relatedness are sometimes placed together in educational research without regard for the important differences between these two components. Meanwhile, Durksen et al. (2016) opined that the concept of relatedness in educational research has been ignored especially within the online environment. Earlier, Chen and Jang (2010) concluded that in the online learning context, there is a need for instructors to implement strategies that cater to the three basic needs of autonomy, competence and relatedness. This was later confirmed by a study conducted by Bissessar (2014) with ten online Bachelor students which indicated that student/student interaction and student/teacher interactions impacted programme completion for online students in the Caribbean.

Put simply, Ryan and Deci (2000) indicated that these components propel students to action, keep students motivated, and determine their personal well-being. In their studies on the relationship of competence, relatedness and autotomy, Ryan and Deci (2000) found that individuals who worked in environments where they were completely ignored by another individual in the room tended to show lower levels of intrinsic motivation. This indicates that individuals' intrinsic motivation is influenced by their relationship with others. According to Ryan and Deci (2000), when an individual wants another individual to perform a specific task, this can lead to passive compliance, amotivation- unwillingness, or active personal commitment or as 
Guay, Villerand, and Blanchard (2000) stated, "individuals experience a lack of contingency between their behaviours and outcomes" (p.177). These variations in behaviours indicate whether the individual has internalized and integrated the value of the task to be performed.

According to Ryan and Deci (2000), externally regulated behaviours are performed to "satisfy an external demand or reward contingency" (p.72) and is related to operant conditions based on behaviourism (citing Skinner, 1953). Therefore, individuals perform tasks based on threats and/or rewards (Harnett et al., 2011; Filak \& Nicolini, 2018). Introjected regulation encompasses "taking in a regulation but not fully accepting it as one's own" (Ryan \& Deci, 2000; p.72). Individuals perform behaviours to avoid feelings of guilt, anxiety, to satisfy the ego or because they feel pressured (Filak \& Nicolini, 2018; Joo, So, \& Kim, 2018). As such, introjection may be contingent upon the level of the person's self-esteem (Ryan \& Deci, 2000).

In contrast, identified regulation is where individuals engage in a task because the task has personal value to them and they see the task as worthwhile (Deci \& Ryan, 2000; Filak \& Nicolini, 2018; Harnett et al., 2011). Integration involves full autonomy where individuals perform the task because of "its significance to their sense of self" (Harnett et al., 2011; p.23). At this stage, assimilation of the task with the individual's values and needs takes place, the process of which becomes intrinsically motivating (Filak \& Nicolini, 2018). For example, one individual engages in an activity due to the pleasure which he/she derives from performing the activity, which is integrated/intrinsic motivation and is at the higher end of the continuum. The other person performs the same activity out of necessity which is identified motivation. All of these components are seen to be along a continuum from amotivation which is the least motivation to intrinsic motivation which is the maximum self-determined motivation (Chen \& Jang, 2010). According to Deci and Ryan (1991), intrinsic motivation and identified regulation can result in positive outcomes whilst amotivation, external and introjected motivation can lead to negative outcomes.

\section{Self-Determination Theory and Online Learning}

Within the online environment, more studies have been conducted on intrinsic motivation as opposed to extrinsic motivation (Harnett et al., 2011). According to Held, Thoma, and Thomas (2004) an individual's self-determination increases and/or decreases based on his/her interaction with key persons in his/ her life. Additionally, Chen and Jang (2010) indicated that the selfdetermination theory of motivation is especially suited to the online environment because its three constructs: relatedness, competency and autonomy are linked to the benefits of online learning such as "flexible learning (Moore, 1993), computer mediated communication and social interaction (Gunawardena, 1995), and challenges for learning technical skills (Howland \& Moore, 2002)" (p.742).

This was later corroborated by Filak and Nicolini (2018) in their study of 240 college students in online and face-to-face classes where they found that higher quality motivation results in higher satisfaction of competence, autonomy and relatedness. In fact, they viewed the online students' locus of control, self-directed learning and autonomy as inextricably linked. However, when they conducted a t-test, they concluded that lower levels of competence, autonomy and relatedness were reported among online students.

Previously, Durksen et al. (2016) conducted a study of 1, 057 participants form 88 countries and determined that a probabilistic relationship exists among the variables of autonomy competence and relatedness. They concluded that participants with "high autonomy had an $80.01 \%$ probability of having a moderate level of competence" (p.242). Although autonomy and competence share a significant relationship, relatedness was mutually exclusive among the 
participants in their study. On the other hand, Joo, So, and Kim (2018) conducted a study of 22 Korean university students and found that their self-determination did not have an effect on their satisfaction with the K-MOOC course. This shows that the findings of these studies cannot be generalized to represent a more global population. Such disparity in conclusions illustrate a need for more expansive research to be conducted on online students' autonomy, relatedness and competence.

Furthermore, Chen and Jang (2010) as well as Filak and Nicolini (2018) continued a discussion as to the tenability of the self-determination theory in depicting individual and collective motivation within the online environment. For example, Mullen and Tallent-Runnels (2006) as well as Filak and Nicolini (2018) concluded that differences in students' perceptions of their teachers and the online learning environment were directly correlated to their motivation. More specifically, Filak and Nicolini's review of the literature revealed that, in a face-to-face environment, satisfying all three components of SDT correlated to positive instructor reviews. However, in online classes, correlation was found only competence and relatedness. The authors posited possible reasons including the lack of immediate interaction with faculty generating doubtful perceptions amongst the students. Studies in the self-determination theory in the online environment have shown that understanding students' motivation can predict students' performance, persistence, satisfaction as well as their learning needs.

\section{Methodology}

Quantitative methodology allowed the researchers to target a wider population of current and former students. Designed to capture the experiences of online students affecting persistence, the survey was constructed by the researchers based on the self-determination theory espoused by Ryan and Deci (1985). Questions were aligned to the components of the self-determination theory (relatedness, competence, and autonomy) while worded to reflect known behaviours associated with national cultural values (Hofstede, 2018; LeBaron, 2003a; LeBaron 2003b). Classification of the economic develop of students' home country (developed vs. lesserdeveloped) was based upon the classification of internationally-recognized MSCI (2018). A confidence level of the piloted study was obtained and the Cronbach Alpha of .801 was found. The pilot survey was completed by 14 online graduate students on the $11^{\text {th }}$ October to $23^{\text {rd }}$ October, 2017, taking approximately 15 minutes to complete with no issues. It was then launched to the University of Liverpool Online Masters and Doctoral students December 2017 through July, 2018 via email, LinkedIn and University announcements.

A convenience sample was used to email surveys to potential participants. The survey consisted of 16 statements asking online graduate Masters and Doctoral students to rate statements on components of the self-determination theory (autonomy, competence and relatedness) as being bighly important (5) to no impact (1). Twenty alumnus and 34 current students completed the online survey with 23 females and 31 males. Forty-three respondents ranged in age from 31-50, older millennials and Generation X age cohorts. Four were under age 30 (millennials), six age 51-60 and 1 participant was over age 60. Figure 1 shows a frequency count of the online students' primary countries of residence while enrolled in the programme. It can be seen that most participants came from Canada, Nigeria, UAE, UK and the US. 


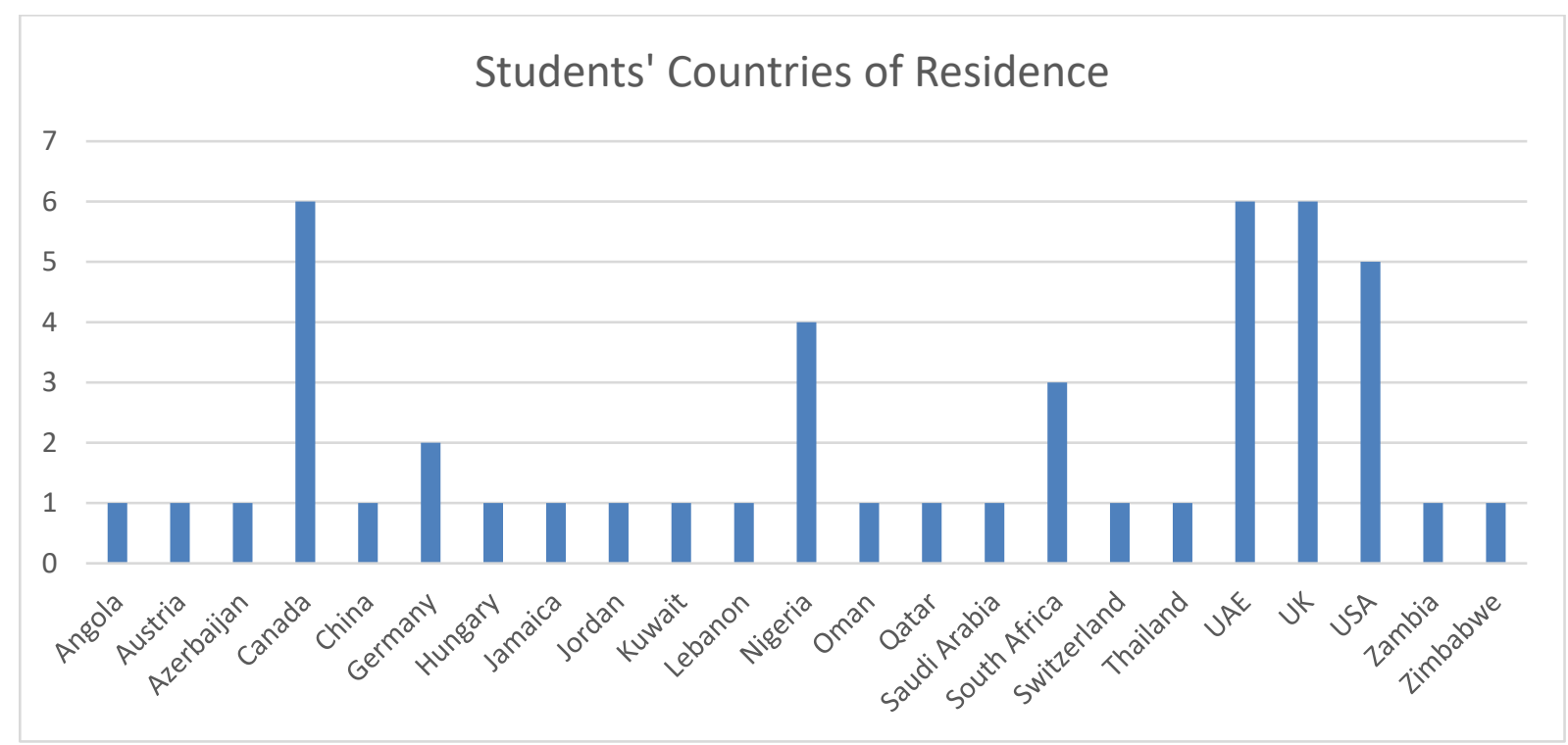

Figure 1. Primary country of residence while enrolled in the programme

\section{Findings}

\section{Autonomy}

From Table 1, it can be seen that 29 students indicated that duty and honour were highly important to them, with a total of 42 students finding this impactful. This correlates with historic research that autonomy is associated with an internal locus of control and was an important factor in ensuring that they persisted (Ryan \& Connell, 1989; Pelletier et al., 2001). Relating this to the national cultural value dimension of communitarianism, the importance of honour and duty was mirrored across both collectivist and individualistic cultures. It further supports the possibility that individuals' internal locus of control weighed more heavily upon their persistence than cultural influences.

Table 1: Autonomy Q 5: I persevered because duty and honour are important to me.

\begin{tabular}{lcccccc}
\hline & Frequency & Percent & $\begin{array}{c}\text { Valid } \\
\text { Percent }\end{array}$ & $\begin{array}{c}\text { Cumulative } \\
\text { Percent }\end{array}$ & $\begin{array}{c}\text { Collectivist } \\
\text { Culture }\end{array}$ & $\begin{array}{c}\text { Individualistic } \\
\text { Culture }\end{array}$ \\
\hline $\begin{array}{l}\text { 1 = No impact on } \\
\text { my perseverance }\end{array}$ & 4 & 7.4 & 7.4 & 7.4 & 3 & 1 \\
$\begin{array}{l}2=\text { Less important } \\
\text { to me }\end{array}$ & 1 & 1.9 & 1.9 & 9.3 & 0 & 1 \\
$\begin{array}{l}3=\text { Neutral or } \\
\text { somewhat }\end{array}$ & 7 & 13.0 & 13.0 & 22.2 & 3 & 4 \\
$\begin{array}{l}\text { important } \\
\begin{array}{l}4=\text { Important to } \\
\text { me }\end{array}\end{array}$ & 13 & 24.1 & 24.1 & 46.3 & 7 & 5 \\
$\begin{array}{l}5=\text { Highly } \\
\text { important }\end{array}$ & 29 & 53.7 & 53.7 & 53.7 & 14 & 15 \\
Total & 54 & 100.0 & 100.0 & & 27 & 27 \\
\hline
\end{tabular}

Table 2 shows that 31 participants rated as highly important that they will do whatever it takes to sustain enrolment and attain success; a total of $47(87 \%)$ agree to the importance of this. Selfregulated learners are intrinsically motivated and have disciplined themselves in goal achievement (Cho \& Heron, 2015). Self-regulation is the manifestation of the motivation in self-determination. 
This relates to Filak and Niolini's views (2018) that online students who are successful tend to be self-directed and show a high internal locus of control.

Table 2: Autonomy Q 11: I will do whatever is necessary (and even beyond) to sustain enrolment and attain success.

\begin{tabular}{|c|c|c|c|c|c|}
\hline & & Frequency & Percent & Valid Percent & $\begin{array}{c}\text { Cumulative } \\
\text { Percent }\end{array}$ \\
\hline \multirow{6}{*}{$\frac{.0}{\bar{\pi}}$} & $\begin{array}{l}1=\text { No impact on my } \\
\text { perseverance }\end{array}$ & 1 & 1.9 & 1.9 & 1.9 \\
\hline & $2=$ Less important to me & 1 & 1.9 & 1.9 & 3.7 \\
\hline & $\begin{array}{l}3=\text { Neutral or somewhat } \\
\text { important }\end{array}$ & 5 & 9.3 & 9.3 & 13.0 \\
\hline & $4=$ Important to me & 16 & 29.6 & 29.6 & 42.6 \\
\hline & $5=$ Highly important & 31 & 57.4 & 57.4 & 100.0 \\
\hline & Total & 54 & 100.0 & 100.0 & \\
\hline
\end{tabular}

Part 2 of the survey captured the lived challenges students faced while attending studies: accessibility (weather, infrastructure/Internet connectivity and devices used), frequency of occurrence of common life challenges (unexpected work demands, unexpected family demands, common or extreme illness or death in family), occurrence of uncommon socio-political challenges (political turmoil/government interference, violence, crime, genocide, economic recession, poverty). Table 3 shows that 24 participants indicated that the challenges faced did not demotivate them or depress them but made them more persistent to continue their studies. Again, emotional control (overcoming anxiety, depression, frustration, etc.) is a behaviour exhibited by self-regulated learners and lack of emotional control inversely relates to intrinsic motivation (Cho \& Heron, 2015). One-fourth of our study's participants experienced this inverse effect, with emotions from challenges affecting their motivation. This shows the characteristic of autonomy and displays resilience on the part of three-fourths of the participants. This is notable given that over half of the participants are from lesser developed countries in which the challenges surveyed are more prevalent (Clarida et al., 2015; OECD, 2017). Moreover, the residual effects of the 2008 worldwide recession were still being "felt" during the attendance of some students.

Table 3: Autonomy Q 15: The challenges rated in Part 2 (above) depressed or demotivated me and made it difficult to persist in my studies.

\begin{tabular}{|c|c|c|c|c|c|}
\hline & & Frequency & Percent & Valid Percent & Cumulative Percent \\
\hline \multirow{6}{*}{$\frac{\overline{\frac{0}{\sigma}}}{\frac{\pi}{\pi}}$} & $1=$ No impact on my perseverance & 24 & 44.4 & 44.4 & 44.4 \\
\hline & $2=$ Less important to $\mathrm{me}$ & 3 & 5.6 & 5.6 & 50.0 \\
\hline & $3=$ Neutral or somewhat important & 14 & 25.9 & 25.9 & 75.9 \\
\hline & $4=I m p o r t a n t$ to $m e$ & 10 & 18.5 & 18.5 & 94.4 \\
\hline & $5=$ Highly important & 3 & 5.6 & 5.6 & 100.0 \\
\hline & Total & 54 & 100.0 & 100.0 & \\
\hline
\end{tabular}

\section{Competence}

Problem solving (our question 6) by its nature bears the assumption that choices and alternatives are available and a solution is possible, breeding/evidencing autonomy. It is an action of selfreliance (question 7), exerting control over life situations as per question 8. It requires and implies the confidence to do so (question 9). However, there are various ways one can accomplish this. Students may see all of this as important to persistence yet not perceive themselves as having the 
"natural ability to redirect paths and find ways of accomplishing goals" (question 10). This perceived control over their situation feeds into their overall perceived competence of their abilities to complete the programme. Thus, the self-perception is of their overall capability rather than specific subject or task-related ability. If, as Durksen et al. (2016) posit when citing Niemiec and Ryan (2009), "The need for competence, however, can be satisfied by experiencing behaviour as effectively enacted" (2016, p.244), then self-management and life-management behaviours enabling continuation in their studies is also an important form of competence necessary to motivate persistence. Our survey results in this bank of questions indicate that participants' level of competence related to programme success was high.

Table 4 shows that 23 participants indicated that problem-solving is the most effective manner of resolving situations that threaten the completion of a module. Collectively, only eight $(15 \%)$ did not engage or value problem solving as an approach to challenges whereas two-thirds found it important.

Table 4: Competence Q6: Problem-solving is the most effective manner of resolving situations that threaten the completion of my modules.

\begin{tabular}{lcccc}
\hline & Frequency & Percent & $\begin{array}{c}\text { Valid } \\
\text { Percent }\end{array}$ & $\begin{array}{c}\text { Cumulative } \\
\text { Percent }\end{array}$ \\
\hline 1 = No impact on my perseverance & 5 & 9.3 & 9.3 & 9.3 \\
2 = Less important to me & 3 & 5.6 & 5.6 & 14.8 \\
3 = Neutral or somewhat & 10 & 18.5 & 18.5 & 33.3 \\
$\overline{\frac{.0}{5}}$ important & 13 & 24.1 & 24.1 & 57.4 \\
$4=$ Important to me & 23 & 42.6 & 42.6 & 100.0 \\
5 = Highly important & 54 & 100.0 & 100.0 & \\
Total & & & & \\
\hline
\end{tabular}

Table 5 shows that 50 participants $(93 \%)$ indicated they relied upon their self-determination to motivate them to persevere within the online environment, with 42 saying it is highly important.

Table 5: Competence Q 7: I have always relied upon my self-determination as my primary motivator to persevere.

\begin{tabular}{|c|c|c|c|c|c|}
\hline & & Frequency & Percent & $\begin{array}{c}\text { Valid } \\
\text { Percent }\end{array}$ & $\begin{array}{c}\text { Cumulative } \\
\text { Percent }\end{array}$ \\
\hline \multirow{5}{*}{$\frac{.0}{\bar{\pi}}$} & $2=$ Less important to me & 2 & 3.7 & 3.7 & 3.7 \\
\hline & $\begin{array}{l}3=\text { Neutral or somewhat } \\
\text { important }\end{array}$ & 2 & 3.7 & 3.7 & 7.4 \\
\hline & $4=\operatorname{Important}$ to $\mathrm{me}$ & 8 & 14.8 & 14.8 & 22.2 \\
\hline & $5=$ Highly important & 42 & 77.8 & 77.8 & 100.0 \\
\hline & Total & 54 & 100.0 & 100.0 & \\
\hline
\end{tabular}

Table 6 shows that 49 participants $(91 \%)$ indicated that they do exert control over their life situation and ensure that they achieve their goals, with 36 indicating this was highly important. This is related to their level of competence and also autonomy and is in keeping with findings by Filak and Niolini (2018) that online students possess a high locus of control and belief in their competence. 
Table 6: Competence Q 8: I should, and do exert control over my life situations to ensure I achieve my goals.

\begin{tabular}{lcccc}
\hline & Frequency & Percent & $\begin{array}{c}\text { Valid } \\
\text { Percent }\end{array}$ & $\begin{array}{c}\text { Cumulative } \\
\text { Percent }\end{array}$ \\
\hline 1 = No impact on my perseverance & 1 & 1.9 & 1.9 & 1.9 \\
3 = Neutral or somewhat & 4 & 7.4 & 7.4 & 9.3 \\
음 important & 13 & 24.1 & 24.1 & 33.3 \\
\hline 4 = Important to me & 36 & 66.7 & 66.7 & 100.0 \\
5 = Highly important & 54 & 100.0 & 100.0 & \\
Total & & &
\end{tabular}

Table 7 shows that 50 students (93\%) indicated that they had the confidence to take on and put in the necessary effort to succeed at overcoming challenges, with 39 finding this highly important.

Table 7: Competence Q 9: I have confidence to take on and put in the necessary effort to succeed at overcoming challenges.

\begin{tabular}{|c|c|c|c|c|c|}
\hline & & Frequency & Percent & $\begin{array}{l}\text { Valid } \\
\text { Percent }\end{array}$ & $\begin{array}{l}\text { Cumulative } \\
\text { Percent }\end{array}$ \\
\hline \multirow{5}{*}{$\frac{.0}{\frac{0}{\pi}}$} & $1=$ No impact on my perseverance & 2 & 3.7 & 3.7 & 3.7 \\
\hline & $\begin{array}{l}3=\text { Neutral or somewhat } \\
\text { important }\end{array}$ & 2 & 3.7 & 3.7 & 7.4 \\
\hline & $4=\operatorname{Important}$ to $\mathrm{me}$ & 11 & 20.4 & 20.4 & 27.8 \\
\hline & $5=$ Highly important & 39 & 72.2 & 72.2 & 100.0 \\
\hline & Total & 54 & 100.0 & 100.0 & \\
\hline
\end{tabular}

Finally, Table 8 shows that only 25 participants indicated their natural ability to redirect paths and find ways of accomplishing goals was highly important to them. However, combined with students who found its importance of significance, again 90\% (48 students) perceive themselves as having this natural ability and that it is important to their persistence.

Table 8: Competence Q 10: My natural ability to redirect paths and find ways of accomplishing goals.

\begin{tabular}{|c|c|c|c|c|c|}
\hline & & Frequency & Percent & $\begin{array}{c}\text { Valid } \\
\text { Percent }\end{array}$ & $\begin{array}{c}\text { Cumulative } \\
\text { Percent }\end{array}$ \\
\hline \multirow{5}{*}{$\frac{\overline{\underline{O}}}{\frac{\pi}{5}}$} & $2=$ Less important to me & 1 & 1.9 & 1.9 & 1.9 \\
\hline & $\begin{array}{l}3=\text { Neutral or somewhat } \\
\text { important }\end{array}$ & 5 & 9.3 & 9.3 & 11.1 \\
\hline & $4=\operatorname{Important}$ to $\mathrm{me}$ & 23 & 42.6 & 42.6 & 53.7 \\
\hline & $5=$ Highly important & 25 & 46.3 & 46.3 & 100.0 \\
\hline & Total & 54 & 100.0 & 100.0 & \\
\hline
\end{tabular}

\section{Relatedness}

Relatedness in self-determination theory is viewed as one of three psychological needs usually met through relationship. The satisfaction of this need is a motivator. SDT research typically looks as classroom factors such as student-student interaction and student-teacher interaction. Our study examined relatedness external to the programme and its affect upon their perseverance in the programme (questions 1-4) as well as belongingness in the classroom (questions 12 and 13), with question 16 relating to both. 
Tables 9-12 provide results for this first set of questions, the external relationships and perceptions of others upon one's own motivation. The importance of students' perception of the expectations others hold of their success was high (Table 9), with 38 students indicating its importance. This mirrors results found with Question 5 measuring autonomy. However, questions 2-4 (Tables 10-12) indicate perception of status gained from the Liverpool degree in terms of self-perception or inclusion in family/friends was only moderately high.

Table 9: Relatedness Q 1: The expectations of you held by others who are important in your life (family members, close friends or peers).

\begin{tabular}{lcccc}
\hline & Frequency & Percent & $\begin{array}{c}\text { Valid } \\
\text { Percent }\end{array}$ & $\begin{array}{c}\text { Cumulative } \\
\text { Percent }\end{array}$ \\
\hline 1 = No impact on my perseverance & 5 & 9.3 & 9.3 & 9.3 \\
2 = Less important to me & 1 & 1.9 & 1.9 & 11.1 \\
3 = Neutral or somewhat & 10 & 18.5 & 18.5 & 29.6 \\
$\overline{\overline{5}}$ important & 14 & 25.9 & 25.9 & 55.6 \\
$4=$ Important to me & 24 & 44.4 & 44.4 & 100.0 \\
5 = Highly important & 54 & 100.0 & 100.0 & \\
Total & & & & \\
\hline
\end{tabular}

Table 10: Relatedness Q 2: The perceived status or power associated with being a Univ. of Liverpool student.

\begin{tabular}{lcccc}
\hline & Frequency & Percent & $\begin{array}{c}\text { Valid } \\
\text { Percent }\end{array}$ & $\begin{array}{c}\text { Cumulative } \\
\text { Percent }\end{array}$ \\
\hline 1 = No impact on my perseverance & 9 & 16.7 & 16.7 & 16.7 \\
2 = Less important to me & 2 & 3.7 & 3.7 & 20.4 \\
3 = Neutral or somewhat & 11 & 20.4 & 20.4 & 40.7 \\
$\overline{\frac{.0}{5}}$ important & 22 & 40.7 & 40.7 & 81.5 \\
$4=$ Important to me & 10 & 18.5 & 18.5 & 100.0 \\
5 = Highly important & 54 & 100.0 & 100.0 & \\
Total & & & & \\
\hline
\end{tabular}

Table 11: Relatedness Q 3: The respect others hold for you as a Univ. of Liverpool student.

\begin{tabular}{lcccc}
\hline & Frequency & Percent & $\begin{array}{c}\text { Valid } \\
\text { Percent }\end{array}$ & $\begin{array}{c}\text { Cumulative } \\
\text { Percent }\end{array}$ \\
\hline 1 = No impact on my perseverance & 8 & 14.8 & 14.8 & 14.8 \\
2 = Less important to me & 2 & 3.7 & 3.7 & 18.5 \\
$\overline{\frac{0}{\sqrt{5}} \quad \text { important }}$ & 15 & 27.8 & 27.8 & 46.3 \\
4 = Important to me & 19 & 35.2 & 35.2 & 81.5 \\
5 = Highly important & 10 & 18.5 & 18.5 & 100.0 \\
Total & 54 & 100.0 & 100.0 & \\
\hline
\end{tabular}


Table 12: Relatedness Q 4: The feeling of inclusion with family, friends and/or peers experienced by attending and/or graduating from a Univ. of Liverpool online programme.

\begin{tabular}{lcccc}
\hline & Frequency & Percent & $\begin{array}{c}\text { Valid } \\
\text { Percent }\end{array}$ & $\begin{array}{c}\text { Cumulative } \\
\text { Percent }\end{array}$ \\
\hline 1 = No impact on my perseverance & 10 & 18.5 & 18.5 & 18.5 \\
2 = Less important to me & 3 & 5.6 & 5.6 & 24.1 \\
3 = Neutral or somewhat & 15 & 27.8 & 27.8 & 51.9 \\
$\overline{\bar{N}}$ important & 14 & 25.9 & 25.9 & 77.8 \\
$4=$ Important to me & 12 & 22.2 & 22.2 & 100.0 \\
5 = Highly important & 54 & 100.0 & 100.0 & \\
Total & & & & \\
\hline
\end{tabular}

Moving onto the questions that pertained to the online learning environment, from Table 13, it can be seen that the sense of belonging and relatedness are linked. Here, 32 online graduate students indicated that they thought interactions in discussions which generated a sense of inclusion were important or highly important to them. This is in agreement with Baumeister and Leary (1995), and Filak and Nicolini's (2018) view of the symbiotic relationship that the sense of belonging and relatedness share.

Table 13: Relatedness Q 12: The interaction with classmates provided a sense of inclusion or belonging in my programme.

\begin{tabular}{|c|c|c|c|c|c|}
\hline & & Frequency & Percent & $\begin{array}{c}\text { Valid } \\
\text { Percent }\end{array}$ & $\begin{array}{c}\text { Cumulative } \\
\text { Percent }\end{array}$ \\
\hline \multirow{6}{*}{$\frac{.0}{\bar{N}}$} & 1 = No impact on my perseverance & 6 & 11.1 & 11.1 & 11.1 \\
\hline & $2=$ Less important to me & 4 & 7.4 & 7.4 & 18.5 \\
\hline & $\begin{array}{l}3=\text { Neutral or somewhat } \\
\text { important }\end{array}$ & 12 & 22.2 & 22.2 & 40.7 \\
\hline & $4=\operatorname{Important}$ to $\mathrm{me}$ & 14 & 25.9 & 25.9 & 66.7 \\
\hline & $5=$ Highly important & 18 & 33.3 & 33.3 & 100.0 \\
\hline & Total & 54 & 100.0 & 100.0 & \\
\hline
\end{tabular}

Internalization of motivation takes place, in part, through interactions with the classroom environment (including its materials) and is affected by students' emotional engagement (Pentaraki \& Burkholder, 2017). Students' interest in the subject being studied is heightened by the manner in which that subject is presented in learning materials, class design, and discussions Their excitement, or lack thereof, affects emotional contagion and classroom climate which affects the engagement of all in the classroom discussions and interrelations between students. Table 14 shows that a very high number of the participants (44) found the material studied and/or sense of enjoyment experienced to be of importance. 
Table 14: Relatedness $Q$ 13: The interesting material studied and/or sense of enjoyment experienced in this programme motivated me to persist in completing it.

\begin{tabular}{lcccc}
\hline & Frequency & Percent & $\begin{array}{c}\text { Valid } \\
\text { Percent }\end{array}$ & $\begin{array}{c}\text { Cumulative } \\
\text { Percent }\end{array}$ \\
\hline 1 = No impact on my perseverance & 2 & 3.7 & 3.7 & 3.7 \\
2 = Less important to me & 3 & 5.6 & 5.6 & 9.3 \\
3 = Neutral or somewhat & 5 & 9.3 & 9.3 & 18.5 \\
$\overline{\overline{0}}$ important & 23 & 42.6 & 42.6 & 61.1 \\
$4=$ Important to me & 21 & 38.9 & 38.9 & 100.0 \\
5 = Highly important & 54 & 100.0 & 100.0 & \\
Total & & & & \\
\hline
\end{tabular}

Table 15 shows that only 9 students indicated that life challenges external to the classroom inspired them to try all the more to complete their studies. Most participants were neutral or indicated that the challenges were less important or had no impact. This correlates to question 14 , intending to determine if the importance of prestige, power, status etc. to their relationships and belongingness would offset the negative impact of challenges. The results here mirror those of questions $2-4$.

Table 15: Relatedness or Competence Q 14: The challenges rated in Part 2 (above) inspired me to try all the more and complete my studies.

\begin{tabular}{|c|c|c|c|c|c|}
\hline & & Frequency & Percent & $\begin{array}{c}\text { Valid } \\
\text { Percent }\end{array}$ & $\begin{array}{c}\text { Cumulative } \\
\text { Percent }\end{array}$ \\
\hline \multirow{6}{*}{$\frac{.0}{\sqrt{\pi}}$} & 1 = No impact on my perseverance & 9 & 16.7 & 16.7 & 16.7 \\
\hline & $2=$ Less important to me & 3 & 5.6 & 5.6 & 22.2 \\
\hline & $\begin{array}{l}3=\text { Neutral or somewhat } \\
\text { important }\end{array}$ & 14 & 25.9 & 25.9 & 48.1 \\
\hline & $4=\operatorname{Important}$ to $\mathrm{me}$ & 19 & 35.2 & 35.2 & 83.3 \\
\hline & $5=$ Highly important & 9 & 16.7 & 16.7 & 100.0 \\
\hline & Total & 54 & 100.0 & 100.0 & \\
\hline
\end{tabular}

Table 16 shows that 5 participants believed that their ability to succeed is reliant upon others, which then affects their motivation to persevere. This shows that the participants were more autonomous and less dependent on each other. Thus, while the expectations put upon them by others were important to them (question 1) as well as feeling included in the classroom and motivated by the study (questions 12 and 13), their high intrinsic motivation and autonomy is reflected inversely in the results of this question. This also implies that cultural communitarianism has a lesser effect upon their motivation.

Table 16: Relatedness $Q$ 16: I believe my ability to succeed is reliant upon others, which then affects my motivation to persevere.

\begin{tabular}{lcccc}
\hline & Frequency & Percent & $\begin{array}{c}\text { Valid } \\
\text { Percent }\end{array}$ & $\begin{array}{c}\text { Cumulative } \\
\text { Percent }\end{array}$ \\
\hline 1 = No impact on my perseverance & 25 & 46.3 & 46.3 & 46.3 \\
2 = Less important to me & 6 & 11.1 & 11.1 & 57.4 \\
3 = Neutral or somewhat & 9 & 16.7 & 16.7 & 74.1 \\
$\overline{\frac{.0}{5}}$ important & 9 & 16.7 & 16.7 & 90.7 \\
$4=$ Important to me & 5 & 9.3 & 9.3 & 100.0 \\
5 = Highly important & 54 & 100.0 & 100.0 & \\
Total & & & & \\
\hline
\end{tabular}




\section{Correlational Matrix}

$\mathrm{H} 1_{0}$ : There is not statistical significance among the variables of autonomy, competence and relatedness when a correlational matrix is performed.

Based on the findings in Table 17, a correlational matrix was performed using MS Excel Mega Stats Add-Ins and several correlations were found. The brightness of the yellow in Table 17 shows the level of correlation among the variables. For example, the first four questions pertaining to relatedness share a significant correlation when the $p$ value is .01 and a two tail test was conducted.

Table 17: Correlation Matrix for Relatedness

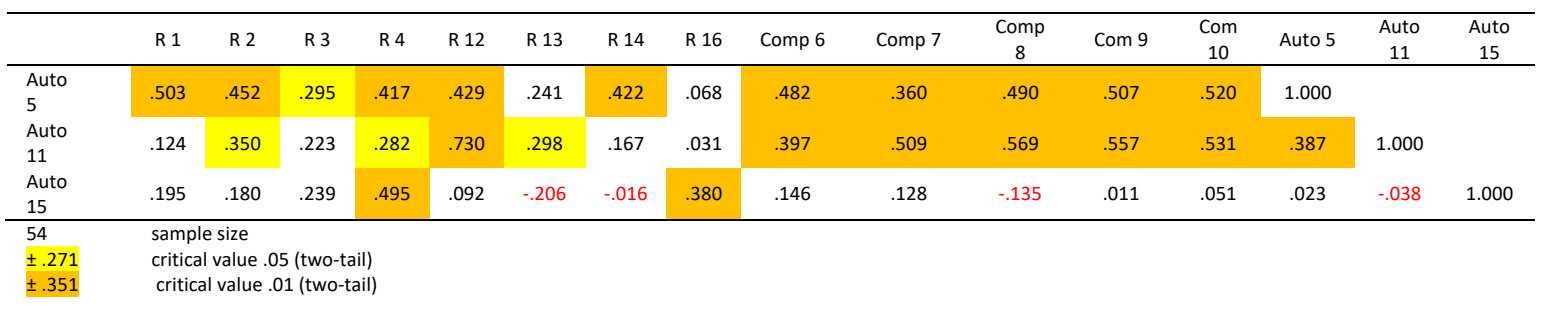

According to Table 18, significant correlations exist between the variables of relatedness and competency when the $p$ value is .01. The most significant correlations can be found in the relatedness questions 4 and 12 and the competence question 6. Significant correlations can also be found among the different questions for competence. For example, competence question 7 has a strong correlation to competence questions 8 and 9 .

Table 18: Correlation Matrix for Relatedness and Competence

\begin{tabular}{lcccccccc}
\hline & R 1 & R 2 & R 3 & R 4 & R12 & R 13 & R 14 & R 16 \\
\hline R 1 & 1.000 & & & & & & & \\
R 2 & .464 & 1.000 & & & & & & \\
R 3 & .468 & .796 & 1.000 & & & & & \\
R 4 & .589 & .489 & .600 & 1.000 & & & & \\
R12 & .218 & .170 & .155 & .447 & 1.000 & & & \\
R 13 & .153 & .212 & .120 & .075 & .318 & 1.000 & & \\
R 14 & .380 & .255 & .319 & .354 & .286 & .136 & 1.000 & \\
R 16 & .137 & .384 & .393 & .297 & .048 & .257 & .041 & 1.000 \\
\hline \pm .271 & critical value .05 (two-tail) & & & & \\
\pm .351 & critical value .01 (two-tail) & & & &
\end{tabular}

Table 19 shows significant correlations among the three variables. For example, relatedness questions 1 and 2 are strongly correlated to autonomy question 5. There is also a strong correlation between all competency questions and autonomous questions 5 and 11 . What is noteworthy is that relatedness questions 13 and 14 and autonomy question 15 share a negative correlation which means that when participants' relatedness increases their autonomy decreases and vice versa. Similarly, competence question 8 and autonomy question 15 share a negative correlation as do autonomy question 15 and autonomy question 11 . Therefore, the null hypothesis has to be rejected since there are statistically significant correlations among the variables. 
Table 19: Correlation Matrix among Relatedness, Competence and Autonomy

\begin{tabular}{|c|c|c|c|c|c|c|c|c|c|c|c|c|c|c|c|c|}
\hline & R 1 & R 2 & R3 & R 4 & R12 & R 13 & R 14 & R 16 & $\begin{array}{c}\text { Comp } \\
6\end{array}$ & $\begin{array}{c}\text { Comp } \\
7\end{array}$ & $\begin{array}{c}\text { Comp } \\
8\end{array}$ & Com 9 & $\begin{array}{c}\text { Com } \\
10\end{array}$ & Auto 5 & $\begin{array}{c}\text { Auto } \\
11\end{array}$ & $\begin{array}{c}\text { Auto } \\
15\end{array}$ \\
\hline $\begin{array}{l}\text { Auto } \\
5\end{array}$ & .503 & .452 & .295 & .417 & .429 & .241 & .422 & .068 & .482 & .360 & .490 & .507 & .520 & 1.000 & & \\
\hline $\begin{array}{l}\text { Auto } \\
11\end{array}$ & .124 & .350 & .223 & .282 & .730 & .298 & .167 & .031 & .397 & .509 & . 569 & .557 & .531 & .387 & 1.000 & \\
\hline $\begin{array}{l}\text { Auto } \\
15\end{array}$ & .195 & .180 & .239 & .495 & .092 & -.206 & -.016 & .380 & .146 & .128 & -.135 & .011 & .051 & .023 & -.038 & 1.000 \\
\hline $\begin{array}{l}54 \\
\pm .271 \\
\pm .351\end{array}$ & $\begin{array}{c}\text { san } \\
\text { cri } \\
\text { cri }\end{array}$ & $\begin{array}{l}\text { alue } \\
\text { alue }\end{array}$ & $\begin{array}{l}\text { wo-ta } \\
\text { wo-ta }\end{array}$ & & & & & & & & & & & & & \\
\hline
\end{tabular}

\section{Conclusions}

Self-determination theory has captured the interest of professionals and researchers alike in its helpfulness towards an understanding of the human behaviour associated with its internalized motivators as well as its interrelatedness to external influences. Rooted in the three needs of autonomy, competence and relatedness, the human experience can be best studied holistically in its realistic context. With this in mind, this study examined not only factors within the classroom environment affecting self-determination to persist but also, and especially, those outside of the classroom: the students' lived experiences of attending school. This study looked at external influencers such as the expectations of family, friends and peers, the perception of status or power gained from the degree, and cultural values. Relatedness, autonomy and self-perception of competence to achieve the programme itself were assessed beyond that of completing class tasks such as homework or discussions.

Under the context of introjected regulation of externally regulated behaviours posited by Deci and Ryan (1985), the potential influence of cultural values upon this must be considered in the global classroom. This study included questions directly attributed to the communitarian values of individualism versus collectivism as defined by Hofstede (2018), whose work is the most widely used typology to capture values in a generalized sense. This dimension addresses "the degree of interdependence a society maintains among its members." (Hofstede, 2018). It captures the degree to which self-image is tied to the family, community and society. Low individualism indicates a collectivist society, with loyalty to the group and relationships of high importance. In this study, the researchers sought to determine whether or not this particular cultural value influenced the components of students' self-determination.

Looking at question 5, duty and honour are specifically named as these are known values associated with collectivist societies (LeBaron, 2003a; 2003b). Duty and honour are a selfperception of one's obligation to others, which is stronger in cultures where an individual's identity and self-image are closely connected with family and society. One might assume the manner in which the question is worded would generate agreement of those from collectivist cultures and lesser agreement of those from individualistic cultures. However, results from either type of culture mirrored the other. It seems values of duty and honour, then, may be tied less to national cultural values and more to students' sense of autonomy with limited impact upon motivation to persist. The results of this study align with the accepted definition of integrated motivation supporting a high internal locus of control.

Self-regulation plays into this, and the researchers considered this particularly in question 11 . The researchers view self-regulated behaviours as the manifestation of internalization of intrinsic motivators. Comparing question 11 to the other results, and having ruled out introjected motivation in question 5 , there is the presence of identified and integrated/intrinsic motivation (Filak \& Niolini, 2018; p.775). 
Finally, relatedness: questions 2-4 (Tables 10-12) indicate perception of status of the Liverpool degree in terms of self-perception or inclusion in family/friends was only moderately high. This should not be discarded. Educators must recognize the impact of an education upon students' relationships outside of class, and vice versa. This should be considered in areas of programme and policy design, advisement and mentoring/guidance. To only look at relatedness and belonging within the classroom environment would prove a myopic view. In this global classroom, there is a need to look at the students' holistically from their perspectives, with their studies being one aspect of their full life, in order to determine best practices for engagement and knowledge construction that motivate perseverance.

While question 13 (pertaining to the materials and subject studied) might be assumed to pertain to competence, its importance is connected to relationships. Pentaraki and Burkholder (2017) stated "You and Kang (2014) found that enjoyment had a mediating effect on the relationship between perceived academic control and self-regulated learning, but the moderating effect of enjoyment was not significant" (p.11). This study, however, found enjoyment to be quite significant in students' perseverance. The internalization of this integrated motivation, according to Deci and Ryan's (1985) Organismic Integration Theory (OIT), is affected by the social environments within which this takes place, thus, tying relatedness to the motivation behind selfdetermination.

\section{Limitations and Recommendations for Further Research}

The possibility that traits remain more influential than cultural values in autonomy provides room to develop an instrument for university advisors and recruiters to help students estimate the struggles that may arise if they choose online education rather than face-to-face classrooms. Additionally, through technology and globalization, worldwide common cohort values of millennials and Generation Z are forming. These 'global cohorts' have developed shared values (Glenn, 2000) which influence individual behaviour along with their own nature (traits) and local cultural values. This study did not use age categories that align with the commonly-accepted categories of generational age cohorts (Baby Boomers, Generation X, Generation Y/Millennial, and Generation Z). Future studies would do well to capture their data within age ranges so as to identify if and how age cohort values affect persistence, specifically in self-determination. Finally, research on online students' determination and persistence typically focus on the classroom and study experience. Remaining understudied is the effect of conquering life challenges (external to the classroom) upon motivation to persist in the programme, filtering into motivation to complete the individual tasks necessary to do so.

\section{References}

1. Baumeister, R., \& Leary, M. R. (1995). The need to belong: Desire for interpersonal attachments as a fundamental human motivation. Psychological Bulletin, 117, 497-529. doi:10.1037/0033-2909.117.3.497

2. Bissessar, C. S. (2014). Students' perceptions of an online B.Ed. programme. Journal of Education and Practice, 5(10), 57-65.

3. Chen, K.-C., \& Jang, S.-J. (2010). Motivation in online learning: Testing a model of self-determination theory. Computers in Human Behaviour, 26(4), 741-752. doi: 10.1016/j. chb.2010.01.011

4. Cho, M., \& Heron, M. (2015). Self-regulated learning: The role of motivation, emotion, and use of learning strategies in students' learning experiences in a self-paced online Mathematics course. Distance Education, 36(1), 80-99. doi:10.1080/01587919.2015.1019963 
5. Clarida, B. H., Bobeva, M., Hutchings, M., \& Taylor, J. (2015). Strategies for Digital Inclusion: Towards a Pedagogy for Embracing and Sustaining Student Diversity and Engagement with Online Learning. LAFOR: Journal of Academic Education, 3(SE). https://doi.org/10.22492/ije.3.se.06

6. deCharms, R. (1968). Personal causation. New York: Academic Press.

7. Deci, E. L. (1975). Intrinsic motivation. New York: Plenum.

8. Deci, E. L., \& Ryan, R. M. (1985). Intrinsic motivation and self-determination in human behaviour. New York: Plenum Press.

9. Deci, E. L., \& Ryan, R. M. (1991). A motivational approach to self: Integration in personality. In R. Dienstbier (Ed.), Nebraska Symposium on motivation: Perspectives on motivation, 38 (pp. 237 288). Lincoln: University of Nebraska Press.

10. Deci, E. L., \& Ryan, R. M. (n.d.) Self-determination theory: Overview. Retrieved from http://selfdeterminationtheory.org/theory/

11. Durksen, T. L., Chu, M.-W., Ahmad, Z. F., Radil, A. I., \& Daniels, L. M. (2016). Motivation in a MOOC: a probabilistic analysis of online learners' basic psychological needs. Social Psychology of Education, 19(2), 241-260. doi:10.1007/s11218-015-9331-9

12. Filak, V. F., \& Nicolini, K. M. (2018). Differentiations in motivation and need satisfaction based on course modality: a self-determination theory perspective. Educational Psychology, 38(6), 772-784. https://doi.org/10.1080/01443410.2018.1457776

13. Glenn, E. (2000). Citizenship and equality: Historical and global perspectives. Social Problems, 47(1), 1-20. doi: 10.2307/3097149

14. Guay, F., Vallerand, J., \& Blanchard, C. (2000). On the Assessment of Situational Intrinsic and Extrinsic Motivation: The Situational Motivation Scale (SIMS). Motivation and Emotion, 24(3), 175-213.

15. Harter, S. (1978). Effectance motivation reconsidered: Toward a developmental model. Human Development, 1, 661-669. https://doi.org/10.1159/000271574

16. Hartnett, M., St. George, A., \& Dron, J. (2011). Examining Motivation in Online Distance Learning Environments: Complex, Multifaceted, and Situation-Dependent. International Review of Research in Open and Distance Learning, 12(6), 20-38. Retrieved from http://www.irrodl.org/index.php/irrodl/article/view/1030/1954

17. Held, M. F., Thoma, C. A., \& Thomas, K. (2004). “The John Jones Show”: How one teacher facilitated self-determined transition planning for a young man with autism. Focus on Autism and Other Developmental Disabilities, 19(3), 177-188.

18. Heo, J. C., \& Han, S. (2018). Effects of motivation, academic stress and age in predicting selfdirected learning readiness (SDLR): Focused on online college students. Education and Information Technologies, 23(1), 61-71.

19. Hofstede, G. (2018). Country Comparison. Hofstede Insights. Retrieved from https://www.hofstede-insights.com/product/compare-countries/

20. Joo, Y. J., So, H.-J., \& Kim, N. H. (2018). Examination of relationships among students' selfdetermination, technology acceptance, satisfaction, and continuance intention to use KMOOCs. Computers \& Education, 122, 260-272. doi: 10.1016/j.compedu.2018.01.003 
21. Kahn, P., Everington, L., Kelm, K., \& Watckins, F. (2017). Understanding student engagement in online learning environment: the role of reflexivity. Educational Technology Research and development, 65(1).

22. LeBaron, M. (2003a) Communication tools for understanding cultural differences. Beyond Intractability. Retrieved from https://www.beyondintractability.org/essay/communication_tools

23. LeBaron, M. (2003b) Cross-cultural communication. Beyond Intractability. Retrieved from https://www.beyondintractability.org/essay/cross-cultural-communication

24. Miltiadou, M., \& Savenye, W. C. (2003). Applying social cognitive constructs of motivation to enhance student success in online distance education. Educational Technology Review, 11(1). Retrieved from https://www.learntechlib.org/p/17795/

25. MSCI (2018). Annual market classification review. Retrieved from https://www.msci.com/market-classification

26. Mullen, G. E., \& Tallent-Runnels, M. K. (2006). Student outcomes and perceptions of instructors' demands and support in online and traditional classrooms. Internet \& Higher Education, 9(4), 257-266. http://dx.doi.org/10.1016/j.iheduc.2006.08.005

27. OECD (2017). Education at a Glance 2017: OECD Indicators. Paris: OECD Publishing. http://dx.doi.org/10.1787/eag-2017-en

28. Pelletier, L. G., Fortier, M. S., Vallerand, R. J., \& Brière, N. M. (2001). Associations Among Perceived Autonomy Support, Forms of Self-Regulation, and Persistence: A Prospective Study. Motivation \& Emotion, 25(4), 279-306. doi: 10.1023/A:1014805132406

29. Pentaraki, A. D., \& Burkholder, G. (2017). Emerging Evidence Regarding the Roles of Emotional, Behavioural, and Cognitive Aspects of Student Engagement in the Online Classroom. European Journal of Open, Distance and E-Learning, 20(1), 1-21. Retrieved from http:/ / www.eurodl.org $/ \mathrm{p}=$ archives\&year $=2017 \&$ halfyear $=1 \&$ article $=736$

30. Reis, H. T. (1994). Domains of experience: Investigating relationship processes from three perspectives. In R. Erber \& R. Gilmour (Eds.), Theoretical frameworks for personal relationships (pp. 87-110). Hillsdale, NJ: Erlbaum.

31. Ryan, R. M., \& Connell, J. P. (1989). Perceived Locus of Causality and Internalization: Examining Reasons for Acting in Two Domains. Journal of Personality and Social Psychology, 57(5), 749-761. doi: 10.1037/0022-3514.57.5.749

32. Ryan, R. M., \& Deci, E. L. (2000). Intrinsic and extrinsic motivations: Classic definitions and new directions. Contemporary Educational Psychology, 25(1), 54-67. doi: 10.1006/ceps.1999.1020

33. Ryan, R. M., Kuhl, J., \& Deci, E. L. (1997). Nature and autonomy: Organizational view of social and neurobiological aspects of self-regulation in behaviour and development. Development and Psychopathology, 9, 701-728.

34. Statista (2018). E-learning and digital education - Statistics \& Facts. Retreieved from https://www.statista.com/topics/3115/e-learning-and-digital-education/

35. White, R. W. (1963). Ego and reality in psychoanalytic theory. New York: International Universities Press. 